\title{
CONFIGURAÇÕES INICIAIS DO ENSINO DE DESENHO NA UNIVERSIDADE FEDERAL DO PARANÁ (1971-1977): DO INSTITUTO DE MATEMÁTICA AO SETOR DE CIÊNCIAS EXATAS
}

\author{
Adriana Vaz* \\ Rossano Silva**
}

\begin{abstract}
RESUMO: Direcionamos o olhar para a forma como as disciplinas de desenho foram formatadas na primeira década da Reforma Universitária, tendo como objeto de estudo o Departamento de Desenho (DDES), da Universidade Federal do Paraná, com o intuito de compreender a matriz do ensino de desenho nessa fase e suas interdependências com outras áreas de conhecimento. Os referenciais teóricos são Elias com os conceitos de figuração e configuração social, Chervel que trata da história das disciplinas e Hernández que aborda a história das matérias curriculares. As fontes utilizadas são as atas das reuniões departamentais. Em síntese, o ensino de desenho ofertado pelo DDES atende aos conteúdos básicos dos Cursos de Engenharia, e, em paralelo, o desenho integra a área de Artes, já que, em 1983, o Departamento de Artes criou o Curso de Educação Artística com habilitação em Artes Plásticas e Desenho, instituindo uma separação entre duas concepções de ensino de desenho: a técnica e a artística.
\end{abstract}

PALAVRAS-CHAVE: Desenho. Educação artística. História da educação.

ABSTRACT: We direct our look to the way how the drawing disciplines have been formatted in the first decade of the University Reform, having

\footnotetext{
* Professora do Departamento de Expressão Gráfica da UFPR, mestre e doutora em Sociologia pela UFPR.

** Professor do Departamento de Expressão Gráfica e do Programa de PósGraduação em Educação: Teoria e Prática de Ensino da UFPR, mestre e doutor em Educação pela UFPR.
} 
as the object of study the Department of Design - DDES of Federal University of Paraná, aiming to understand the drawing teaching matrix in this period and its interdependencies with other areas of knowledge. The theoretical references are Elias with the concepts of figuration and social configuration; Chervel that broaches the history of disciplines and Hernández that broaches the history of curricular subjects. The sources used are the minutes of the Department meetings. In summary, drawing teaching offered by the DDES meets the basic content of the Engineering Courses, and in parallel, drawing integrates the area of Arts, as in 1983 the Arts Department created the Course of Arts Education with qualification in Arts and Drawing, creating a separation between two Drawing teaching concepts: the technical and the artistic.

KEYWORDS: Drawing. Art education. History of education.

\section{Introdução}

O período de 1967 a 1971 marca o início da Reforma Universitária, em que a Universidade Federal do Paraná (UFPR) se organizou em institutos e em faculdades. ${ }^{1}$ Em 1970, o reitor Flávio Suplicy de Lacerda,

[...] ressalta o esforço que era realizado pela Universidade para adaptar-se ao sistema organizacional e operacional decorrente da Reforma Universitária, "com o novo Estatuto aprovado, se estabeleceu a nova estrutura da Universidade, com a divisão do ensino básico nos Institutos, e ensino profissional nas Faculdades,

1 "O Decreto n. 14.923, de $1^{\circ}$ de abril de 1969, instituiu a comissão para tratar da reforma no âmbito da Universidade Federal do Paraná prevista pela Lei $\mathrm{n}$. 5.540/68". (GLASER, 1988, p. 38). Pelo Estatuto da Universidade Federal do Paraná, Decreto n. 66.615, de 21/05/1970, os Institutos foram organizados em seis unidades: Matemática; Física; Geo-ciências; Biologia; Ciências Humanas; Letras e Artes. In: UNIVERSIDADE FEDERAL DO PARANÁ. Boletim Administrativo da Universidade Federal do Paraná, ano XV, n. 186, nov. 1970, p. 27. 
além de modificar os critérios de controle curricular, de formação e a sistemática administrativa”. (LACERDA apud GLASER, 1988, p. 39).

Em consonância com as transformações referentes ao Ensino Superior, em 1962, o Brasil ofertava 112 cursos de Engenharia, sendo que, pela classificação feita em 1966, a profissão era regulamentada nas seguintes modalidades: "engenheiro aeronáutico, agrimensor, agrônomo, cartógrafo, civil, eletricista, eletrônico, de comunicação, florestal, geólogo, mecânico, metalurgista, de minas, naval, de petróleo, químico, industrial, sanitarista, têxtil e de operação" (MEC, 2009, p. 9). Os currículos mínimos, suas ênfases e habilitações foram regulamentados em 1976, momento em que o país estava em crescimento, visto que, no final dessa década, o Brasil viria a ampliar o número de Engenharias para 363 cursos.

Ciente dessa ambiência no que tange à estruturação do Ensino Superior e à ampliação das Engenharias, em hipótese, a UFPR valoriza o ensino do Desenho como conhecimento técnico que fundamenta a profissão do engenheiro. Sendo assim, parte-se do pressuposto de que o Desenho estava vinculado a estruturas distintas na Universidade: de um lado, fruto da matriz institucional que separa o Ensino Básico do Ensino Profissional, pela colocação de Lacerda; de outro, pela história do ensino do Desenho polemizar uma vertente técnica e a outra artística. 2

Com base em Norbert Elias, parte-se da microssociologia e se adota como objeto de estudo o Departamento de Desenho (DDES), que recebe essa denominação em 1974. Com o intuito de traçar o que estava em pauta nessa fase inicial de estruturação do ensino de Desenho no Setor de Ciências Exatas, bem como compreender as interdependências que circunscreviam esse universo e suas figurações delineadas a partir de sua origem no campo da matemática, as principais fontes utilizadas são as atas das reuniões do Departamento, no período de 1971 a 1977.

Metodologicamente, divide-se o estudo em duas partes:

2 Consultar os autores: Barbosa (2006), Nascimento (1994), Osinski (2002). 
a primeira, em função da denominação inicial do próprio Departamento que era conhecido como "Departamento de Desenho e Geometria Descritiva do Instituto de Matemática", fase que abrange o período de 1971 a 1973; a segunda engloba o período de setembro de 1973 a dezembro de 1977, nesse interstício o Departamento passou por duas estruturações. Uma delas se oficializou em dezembro de 1973, quando o Departamento 153, como também era designado, foi absorvido pelo recém-criado e passou a ser vinculado ao Setor de Ciências Exatas ${ }^{3}$ e não mais ao Instituto de Matemática. Outra estruturação se concretizou em meados de junho de 1974 e se estendeu até setembro de 2008, período em que foi batizado como Departamento de Desenho (DDES), uma estrutura separada da área de Matemática.

O Departamento efetiva-se a partir de 1974, na constatação de que seu núcleo de conteúdos disciplinares vigentes nesses anos iniciais irá moldar o ensino de Desenho nessa unidade administrativa, conteúdos voltados à formação básica dos Cursos de Graduação em Engenharia. O que comprova a colocação de Chervel quanto aos "efeitos da escolarização" e fundamentados em Elias (2001) na ideia de figuração. A priori, entendemos que esses conteúdos disciplinares interferirão nas demais práticas vivenciadas pelos docentes - embora neste estudo não iremos abordar as práticas de ensino.

\section{Ensino de Desenho no Instituto de Matemática}

De 15 de setembro de 1971 a 30 de agosto de 1973, o

3 Pela Resolução n. 19/73, do Conselho de Ensino e Pesquisa (CEP), de 26 de setembro de 1973, o Setor de Ciências Exatas é composto pelos Departamentos de: Matemática; Matemática Aplicada e Desenho; Estatística Geral e Aplicada; Química; Física Teórica; Física Experimental; Física Aplicada. Além disso, o Setor foi constituído pelo Instituto de Matemática, Física e a parte básica de Engenharia Química, de acordo com a Portaria n. 10.397, de 5 de setembro de 1973. In: UNIVERSIDADE FEDERAL DO PARANÁ. Boletim Administrativo da Universidade Federal do Paraná, ano XVIII, n. 220, set. 1973, p. 5, 11. 
Departamento estava vinculado ao Instituto de Matemática da Universidade 4 . Segundo Carlos Santos, a Resolução n. 6/70, de 12/11/1970, do Conselho Universitário, para implantação do Instituto, indica que "os docentes foram distribuídos em quatro departamentos: 1) Álgebra e Geometria; 2) Análise Matemática; 3) Desenho e Geometria Descritiva; 4) Computação e Estatística" (SANTOS, 2012, p. 37). Pela denominação do Departamento, em hipótese, o Desenho e a Geometria Descritiva são compreendidos como duas áreas distintas de conhecimento, "sendo o Desenho a maneira pela qual se procede a expressão gráfica", como menciona o Prof. Dr. Orlando Silveira Pereira, ${ }^{5}$ na função de chefe do Departamento.

Após destacar a importância desse ramo do saber, o professor menciona que o Departamento necessita de infraestrutura adequada para o seu funcionamento, e que, "pela reformulação administrativa da Universidade, visa-se a congregar todas as disciplinas afins do Ensino Básico, como pertinentes ao Desenho e Geometria Descritiva, como parte distinta de órgãos similares de uma estrutura" (UFPR, 1971a, s.p.). De imediato, nota-se que o Desenho não é um conteúdo que faça parte dos exames para o aluno ingressar no Ensino Superior, o que pela retórica dos professores resulta na baixa qualidade do ensino, problemática que se estende como tema de pauta das reuniões ao longo dos anos iniciais de conformação do Departamento ${ }^{6}$ (UFPR, 1972b, 1972d, 1972g, 1973a, 1976c, s.p.).

4 De acordo com a Resolução n. 8/70, de 12 de novembro de 1970, o Instituto de Matemática dispunha de 22 professores titulares, 23 professores adjuntos e 56 professores assistentes. In: UNIVERSIDADE FEDERAL DO PARANÁ. Boletim Administrativo da Universidade Federal do Paraná, ano XV, n. 186, nov. 1970 , p. 6.

5 Em 1954, para obtenção da cadeira de Desenho a Mão Livre, escreveu a tese "Novo processo de perspectiva axonométrica" (UFPR, 1971a, s.p.; PEREIRA, 1954).

6 Rosilene B. Machado, ao tratar da história da disciplina de Desenho, tendo como estudo de caso o Colégio de Aplicação da Universidade Federal de Santa Catarina no período de 1960 a 2000, menciona que o fato de o Desenho ter saído do vestibular é uma das causas apontadas pela autora para a desvalorização dessa disciplina. (MACHADO, 2012, p. 98-99). 
Prosseguindo à leitura da ata, vê-se que a base inicial do Departamento eram as disciplinas de Desenho, Geometria Descritiva e Nomografia. Sobre essa questão, o professor Pereira "reitera que devem ser nitidamente consideradas as partes: a) do ciclo básico, que deverá ser geral e b) do ciclo de formação profissional que, forçosamente, terá de ser específico aos diversos ramos profissionais [...]" (UFPR, 1971a, s.p.).

Além das diferentes áreas de formação que o Desenho atendia, observa-se que a Universidade ampliou o número de alunos, o que, consequentemente, tornava necessário ampliar o número de professores:

[...] tendo em vista o atual número de discentes com o acréscimo de cento e vinte por cento, seja prevista a ampliação do Corpo Docente bem como para atender ao ensino em turmas de cerca de 50 alunos e, ademais, deverá ser considerado o curso de Licenciatura em Desenho; [...]. (UFPR, 1971a, s.p.).

Conforme Luiz A. Cunha (2015), na primeira metade da década de 1960, as universidades federais já estavam saturadas em função do binômio cursos-cátedras e da expansão de matrículas, o que cominava a reestruturação das universidades. Mudanças implantadas pelo Decreto-Lei 53/66, que determinou os princípios e as normas de organização das universidades federais, e pela Lei da Reforma Universitária (5.540/68), que impunha às universidades a organização do ensino superior.

O processo de ampliação das universidades federais não era um caso isolado da UFPR. Além disso, o Departamento surge indagando a necessidade de criar um Curso de Licenciatura em Desenho ${ }^{7}$ e problematiza que a Universidade precisa se adequar à ampliação de alunos. Sua estrutura se inicia com os

7 O que atenderia à demanda vigente na Lei n. 5692/71, "Art.30. Exigir-se-á como formação mínima para o exercício do magistério: [...] c) em todo o ensino de $1^{\circ}$ e $2^{\circ}$ graus, habilitação específica obtida em curso superior de graduação correspondente a licenciatura plena". 
seguintes professores, conforme indicado na ata da $1^{\text {a }}$ reunião departamental, realizada no dia 15 de setembro de 1971: Orlando Silveira Pereira, chefe do departamento, Augusto Conte, Eurico Dacheux de Macedo, Jorge Bernard, José Rodolfo de Lacerda, Jurandyr Pavão, Leonilda Auriquio, Lourenço Mourão e Mila Aguilar (UFPR, 1971a, s.p.).

Tomando como base as teses e os livros disponíveis no sistema de bibliotecas da UFPR, do grupo de docentes que integram o Departamento, sinalizam para uma trajetória acadêmica os professores: Orlando Silveira Pereira, Leonilda Auriquio, Mila Aguilar $^{8}$, Jorge Bernard ${ }^{9}$ e Eurico Dacheux de Macedo ${ }^{10}$. Reiterase que, nesta fase do projeto "Abordagem histórica e social do campo da expressão gráfica"11, para delinear a percurso inicial dos docentes do Departamento foram consultados os livros e as teses do sistema de bibliotecas da UFPR, assim como os Boletins Administrativos da UFPR no período de 1970 a 1974, e os Fastos Universitários da UFPR de 1975, 1976 e 1977; entretanto, ainda precisam ser verificados os documentos existentes nos arquivos do Departamento e outras instituições afins.

Quanto às disciplinas e aos conteúdos que deram origem ao ensino de Desenho, interessa-nos o termo "disciplina" como sinônimo de "conteúdos de ensino", denominação que está ausente em todos os dicionários do século XIX, como afirma

8 Em 1987, defende a tese para professora titular denominada "A universidade no tempo da cibernética". Em 1977, publica a tese de livre docência denominada "O número de transporte", e, em 1978, escreve a tese "Interpretação físicoquímica das reações de Meigen", também para professora titular.

9 Durante a década de 1970, escreve livros relacionados à perspectiva: "Axonometria cilíndrica: perspectiva cavaleira" (1972) e "Perspectiva linear cônica: um método gráfico, analítico e mecânico" (1976). Em 1981, defende a tese para obtenção do grau de doutor na L'Université de Nice Geodesie Spatiale.

10 Em 1990, publica o livro "Caminhos para o Paraná do próximo milênio: 28 rotas de transportes" em coautoria com Rafael Greca de Macedo.

11 O projeto teve início em 2015, registrado no Banpesp: 2015018372. Compõem a equipe, os professores: Adriana Vaz, Rossano Silva, Francine A. Rossi e Emilio E. Kavamura. 
Chervel, visto que essa nova acepção da palavra está ligada às renovações da finalidade do Ensino Primário e Secundário, inserida em uma corrente de pensamento pedagógico que se manifesta na segunda metade do século XIX, ou seja, "ela faz par com o verbo disciplinar, e se propaga primeiro como um sinônimo de ginástica intelectual [...]" (CHERVEL, 1990, p. 179).

A ideia de exercício intelectual aparece com o matemático e filósofo Antoine Cournot, mas é com Félix Pécaut e demais estudiosos da renovação pedagógica de 1880 que se propaga como um dos temas fundamentais da nova instrução primária. Portanto, disciplina, "passa a significar uma 'matéria de ensino suscetível de servir de exercício intelectual' [...]" (CHERVEL, 1990 , p. 179). Até 1902, para as Universidades, o modo de formar os espíritos era por meio das "humanidades clássicas", logo, "uma educação que fosse fundamentalmente matemática ou científica não deveria ser, antes do começo do século $X X$, plenamente reconhecida como uma verdadeira formação do espírito" (CHERVEL, 1990, p. 179-180).

Ainda a respeito das diferentes conotações do termo "disciplina", após a I Guerra Mundial, "torna-se uma pura e simples rubrica que classifica as matérias de ensino, fora de qualquer referência às exigências da formação do espírito" (CHERVEL, 1990, p. 180). Concordamos com esse autor, quando menciona que "uma 'disciplina', é igualmente, para nós, em qualquer campo que se a encontre, um modo de disciplinar o espírito, quer dizer de lhe dar os métodos e as regras para abordar os diferentes domínios do pensamento, do conhecimento e da arte" (CHERVEL, 1990, p. 180).

A história das disciplinas abrange um leque de questões que se caracteriza pelo perfil dos seus alunos, dos estabelecimentos de ensino, abarca também a qualidade dos docentes, envolve a relação entre professores e alunos; no caso do Ensino Superior, ela transmite diretamente o saber. Para Hernandez (2000, p. $60)$, o conhecimento de uma matéria curricular avança a partir de estudos que permitem escrever sua história, considerando: o seu papel no currículo escolar, as diversas versões adotadas 
em decorrência das transformações sociais, as concepções disciplinares e a função concebida pela educação vigente, entre outros fatores. Ponderando o objeto de estudo em questão, o Departamento de Desenho e Geometria Descritiva inicia sua trajetória constituindo seus programas de ensino e estabelecendo um núcleo de disciplinas que o represente, conforme será detalhado na sequência.

Em 06 de janeiro de 1972, o tema principal da reunião do Departamento era a aprovação da súmula dos programas para o ano letivo de 1972. Os programas são divididos em cinco grupos de disciplinas: Desenho Geométrico, Geometria Descritiva, Desenho Técnico, Desenho Artístico e Nomografia. Inicialmente, são descritos os conteúdos de Desenho Geométrico e Geometria Descritiva. Esses dois grupos englobam as disciplinas de Desenho Geométrico I e II, Geometria Descritiva I, II e III. ${ }^{12}$

Desenho Geométrico I - Construções geométricas fundamentais. Triângulos. Polígonos regulares; inscrição na circunferência; processos gráficos de traçado. Divisão e medida de ângulo. Cônicas. Concordância. Traçado de curvas e arcos. Arcos abatidos; arcos de cesto de 3, 5 e 7 centros. Falsa elipse. Oval de Cassini. Óvolo. Curvas cíclicas. Evolvente da circunferência. Senóide. Logarítmica. Quadratriz. Catenária. Conchoide: da reta e da circunferência. Cissoide ortogonal. Espirais. Falsas espirais. Voluta. Curvas não geométricas ou gráficas; tangentes e normais. Equivalência. Desenho Geométrico II - Compensação poligonal do setor circular e do segmento parabólico. Divisão de áreas. Integração gráfica. Método de translação. Método de rotação. Métodos de semelhança. Método de homologia. Inversão. Estudo do desenho de ornamentação geométrica.

12 Para o estudo da geometria descritiva, conforme a Ata da reunião departamental de 06 de janeiro de 1972, são indicados os autores: Cavallin (Licões de geometria descritiva, Axonometria cilíndrica, Método de projeção central, Perspectiva linear cônica); Crusat y Daurella (Geometria Descriptive); G. Hawk (Série Schaum - Descriptive Geometry); Benjamin Carvalho (Perspectiva) (UFPR, 1972a, s.p). 
Redes. Disposição ornamental. Ornatos correntes. Geometria Descritiva I - Introdução, objetivos e notações. Homologia plana. Dupla projeção ortogonal; representação dos elementos fundamentais; problemas fundamentais de posição; operações de rebatimento, rotação e mudanças de plano; problemas fundamentais métricos; representação de poliedros. Sistema de projeções cotadas: representação dos elementos fundamentais; condições e problemas de perpendicularidade; operação de rebatimento; problemas fundamentais métricos. Noções de perspectiva linear cônica. Geometria Descritiva II - Representação de poliedros convexos; secções planas. Interseções de poliedros. Axonometria: princípio axonométrico e definição de elementos característicos. Axonometria cilíndrica genérica. Axonometria ortogonal; fórmulas e construções fundamentais. Graduação dos eixos axonométricos. Representação dos elementos fundamentais em axonometria cilíndrica. Perspectiva cavaleira; representação de poliedros. Transformação de sistemas. Rebatimento de plano genérico sobre o quadro. Traços verdadeiros de retas e planos em axonometria ortogonal. Condições e problemas de perpendicularidade. Geometria Descritiva III - Projeção central. Perspectiva linear cônica. Emprego dos pontos medidores e das retas de medidas. Processo axonométrico cônico. Perspectiva em quadro plano inclinado. Representação de curvas. Geração, classificação e representação das superfícies geométricas. Superfícies cônicas e cilíndricas. Esfera. Superfícies de revolução. Teoria geométrica das sombras. Sombra do cilindro, do cone, e da esfera. Sombra na perspectiva. (UFPR, 1972a, s.p., negrito nosso).

Parte desses conteúdos ainda são ministrados pelo Departamento. ${ }^{13}$ Chervel aponta algumas questões que explicam

13 Consultar as ementas vigentes para o ano letivo de 2017, das quais citamos os seguintes códigos: CD014, CD020, CD027, CD028, CD032, CD033, CD034, CD035, CD046, CEG003, CEG004, CEG005, CEG006, CEG012 - exceto as disciplinas do curso de bacharelado em Expressão gráfica. In: DEPARTAMENTO DE EXPRESSÃO GRÁFICA(DEGRAF) - UFPR. Ementas vigentes. Disponível em: <http://www.exatas.ufpr.br/portal/degraf/ementas- 
a dificuldade de se realizar reformas curriculares e particulariza os ensinos escolares: a) o fato de que a instauração das disciplinas ou suas reformas é uma operação de longa duração, em que o procedimento didático utilizado se manifesta após o término da escolaridade do aluno - independentemente de sua qualidade; b) a eternização dos postos e funções que cabe aos docentes; c) a taxa de renovação do corpo docente e sua relação com a evolução das disciplinas; d) a estabilidade de uma disciplina que se consolida por uma experiência pedagógica já enraizada. Quanto à experiência pedagógica, Chervel menciona:

[...] ela se prevalece dos sucessos alcançados na formação dos alunos, assim como de sua eficácia na execução das finalidades impostas. Fidelidade aos objetivos, métodos experimentados, progressões sem choques, manuais adequados e renomeados, professores tanto mais experimentados, quanto reproduzem com seus alunos a didática que os formou em seus anos de juventude, e, sobretudo, o consenso da escola e da sociedade, dos professores e dos alunos: igualmente fatores de solidez e de perenidade para os ensinos escolares. (CHERVEL, 1990, p. 198).

Problemática que nos permite articular a colocação de Chervel com o que Norbert Elias (2001) define como figurações, o elo entre sociedade e indivíduo, em que as mudanças pedagógicas são decorrentes de uma situação social e dos indivíduos envolvidos em suas formulações. Para Chervel:

[...] as leis que mudam as línguas, dizia um obscuro filósofo do século XIX, são as leis que as criam. Dá-se o mesmo com as disciplinas ensinadas. Sua transformação, como sua constituição estão inteiramente inscritas em dois polos: o objetivo a alcançar e a população de crianças e adolescentes a instruir. É aí que se devem encontrar as fontes da mudança pedagógica. Pois é ao mesmo tempo através de suas finalidades e através de seus alunos que elas

vigentes/>. Acesso em: 10 nov. 2017. 
participam da cultura e da vida social de seu tempo. (CHERVEL, 1990, p. 198).

Relacionar as disciplinas, os cursos de graduação e os professores responsáveis por tais conteúdos permite considerar que o DDES é uma figuração - a ser retomada posteriormente -, mesmo que, neste artigo, o objetivo seja registrar a matriz dos conteúdos das disciplinas de Desenho ligadas ao Instituto de Matemática, depois ao Setor de Ciências Exatas e suas possíveis configurações com as Artes; e, em pesquisas futuras, compreender como essa configuração inicial interfere na própria história do Departamento.

No período de 1971 a 1977, dentre as funções descritas nas atas departamentais e que competem aos professores ${ }^{14}$ tem-se: o ensino de graduação, a coordenação de disciplinas, a representação nos colegiados de cursos, os cargos administrativos e a participação em comissões e bancas de concursos. Em 1972, constata-se que, na distribuição de turmas por professor, não é possível identificar os encargos didáticos de cada docente, contudo é possível observar que a maioria dos cursos vinculados ao Departamento mantém em sua grade curricular três disciplinas: Desenho Geométrico, Geometria Descritiva e Desenho Técnico. Em Desenho Geométrico, temos quatro professores: Augusto Conte, Hayton Silva, Jayme M. Cardoso e Leonilda Auriquio; em Geometria Descritiva, assumem as turmas: Gilberto Azeredo Lopes, José R. do Nascimento Jr., Jorge Bernard e Roberto Portugal Alves, perfazendo quatro professores; o Desenho Técnico tem três docentes responsáveis: Clion Dória, Jurandyr Pavão e Orlando S. Pereira; havendo, ainda, mais três professores que assumem os conteúdos de Desenho Técnico com Geometria Descritiva: Jucundido da Silva Furtado, Lourenço da S. Mourão e Mila Aguilar.

14 A carreira do magistério superior para os moldes do período foi regulamentada pelo Ministro da Educação Jarbas Passarinho (1969-1974). Pela Lei n. $5.540 / 68$, o magistério superior no modelo de cátedras foi extinto e se implantaram as classes de titular, adjunto e assistente. 
Ainda referente às atividades de ensino e em comparação à frequência na primeira reunião departamental, amplia-se o número de professores, de nove para dezesseis, sendo que os docentes José Rodolfo de Lacerda e Eurico Dacheux de Macedo não assumem aulas na graduação. Em relação ao interesse na produção acadêmica, estimado pelas publicações disponíveis na biblioteca da UFPR, o intuito inicial era compreender a área de pesquisa do docente na própria universidade em comparação com as disciplinas ministradas na graduação. Também salientamos a atuação dos professores: Clion Dória ${ }^{15}$, Jayme M. Cardoso ${ }^{16}$ e José R. do Nascimento Júnior ${ }^{17}$.

Outra atividade realizada pelos professores era a de coordenadores de disciplinas, que tinham como função resolver os problemas relativos aos locais de aula e horários, para os quais inicialmente foram nomeados os professores titulares e suplentes por disciplina: José Cavallin ${ }^{18}$ e Jayme Cardoso, para Geometria Descritiva; Clion Dória e Leonilda Auriquio, para Desenho Geométrico; e Roberto Portugal Alves, para Desenho Artístico, conforme reunião departamental realizada em 10 de janeiro de 1972.

Transcorridas algumas reuniões, os coordenadores são

15 Escreve os livros: "Química tecnológica e analítica" (1952) e "Curso de Perspectiva e Sombras" (1958).

16 Publica as teses de livre-docência: "A utilidade da representação de Monge na composição e decomposição de forças no espaço" (1953) e "Espaços finitos" (1960); e, para titular: "Sistemas de Projeção" (1977).

17 Em 1987, defende a tese para professor titular denominada "Graduação dos eixos axonométricos, é necessário?", referente às disciplinas de Geometria Descritiva e Desenho Técnico.

18 Em 1948, escreve sua tese para cátedra da Faculdade de Engenharia do Paraná, com o título: "O processo homológico e sua utilidade na representação mongiana". E publica os livros: "Lições de Geometria Descritiva: método da dupla projeção ortogonal e de projeções cotadas" (1950), "Geometria descritiva" (1958), "Método da projeção central: lições de geometria descritiva" (1958), "Lições de geometria descritiva: axonometria mongeana ou sistemas de projeções ortogonais de Monge" (1962), "Perspectiva linear cônica" (1964) e "Axonometria cilíndrica ou paralela: lições de geometria descritiva" (1970). 
renomeados, considerando-se a indicação da disciplina e dos cursos:

O Prof. José Cavallin foi designado coordenador de Geometria Descritiva, dos cursos de Arquitetura e de Engenharia Civil, Mecânica e Eletricista. O Prof. Ildefonso Clemente Puppi foi designado coordenador de Desenho Geométrico do curso de Engenheiros Agrônomos e o Prof. Orlando Silveira Pereira como coordenador de Desenho Técnico nos cursos de Engenheiros Civis, Mecânicos e Eletricistas. (UFPR, 1972c, s.p.).

O coordenador da disciplina de Geometria Descritiva é o único que permanece, na transição de janeiro para março de 1972, sendo que as disciplinas elencadas correspondem aos conteúdos ofertados no $1^{\circ}$ semestre de 1972, ou seja, a disciplina de Desenho Artístico é substituída por Desenho Técnico. Comparando os coordenadores de disciplinas com os professores que assumiram as aulas, o docente Orlando S. Pereira realiza as duas funções e o professor Idefonso Clemente Puppi ${ }^{19}$ não assume atividades de ensino. A mudança na nomenclatura da disciplina de Desenho Artístico para Desenho Técnico mostra que o Departamento direciona seu ensino para um viés mais técnico, o que condiz com o perfil de formação dos professores que deu origem ao Instituto de Matemática - a maioria era proveniente da

19 Em 1958, defende a tese "A imagem perspectiva sobre quadro inclinado", para cátedra da Escola Superior de Agricultura e Veterinária referente à cadeira de Desenho de Aguadas: perspectivas e sombras. Em 1973, escreve a versão preliminar do livro "Noções de estruturação das cidades"; e, em 1976, publica a versão definitiva "A cidade salubre: noções de estruturação das cidades". Na mesma temática, publica "Estruturação sanitária das cidades" (1981). E, em 1986, lança o livro "Fatos e reminiscências da faculdade". Em 1971, é um dos integrantes do Conselho Universitário da UFPR, como representante da Congregação da Faculdade de Engenharia. Também participa do Conselho o professor Jucundino da Silva Furtado, como representante da Congregação da Faculdade de Economia e Administração. In: UNIVERSIDADE FEDERAL DO PARANÁ. Boletim Administrativo da Universidade Federal do Paraná, ano XVI, n. 193, jun. 1971, s.p. 
Faculdade de Engenharia ${ }^{20}$, questão a ser retomada a seguir. Isto também sinaliza que os professores responsáveis por delinear os conteúdos das disciplinas não necessariamente tinham a vivência da sala de aula, pois desempenhavam outras funções administrativas.

A terceira função do professor é representar o Departamento nos colegiados. Na conjuntura em questão, a designação coube a Olavo Del Claro, diretor do Instituto de Matemática, com os seguintes representantes:

Prof. Augusto Conte - Faculdade de Floresta; Prof. Ildefonso Clemente Puppi - Faculdade de Engenharia; Prof. Jorge Bernard - Faculdade de Engenharia Química; Prof. ${ }^{a}$ Leonilda Auriquio Faculdade de Agronomia; Prof. Jayme Machado Cardoso - Instituto de Matemática. (UFPR, 1972b, s.p.).

Até a presente data e com base na representação em colegiado, o Departamento atende os cursos de Licenciado em Matemática e em Ciências, Eletricista, Arquitetura e as Engenharias: Florestal, Agronomia, Civil, Química, Mecânica. Em continuidade às disciplinas que compõem o elenco do Departamento, detalhamos o programa de Desenho Técnico I e II, apresentado na reunião departamental de 06 de janeiro de 1972:

Desenho Técnico I - Desenho e suas espécies; importância como língua técnica. Materiais de desenho. Instrumentos de desenho. Processos de cópia. Reprodução de desenhos: aparelhos e instalações. Transformação e divisão de áreas. Traçado de curva. Concordância. Desenvolvimento de sólidos e superfícies. Interseção de sólidos. Normas técnicas de desenho. Formatos e margens. Dobragem. Letras e algarismos. Composição de Letreiros. Títulos e Legendas. Letras ornamentais. Colorido. Tintas. Aerografia. Figuração convencional. Escalas. Cotagem. Esboços. Croquis

20 In: UNIVERSIDADE FEDERAL DO PARANÁ. Boletim Administrativo da Universidade Federal do Paraná, ano XVI, n. 194, jul. 1971, p. 5-6. 
técnico. Sistemas de representação. Vistas principais. Vistas auxiliares. Desenho Técnico II - Normas Brasileiras. Traços. Letreiros. Legendas. Formatos e Margens. Dobragem. Axonometria cilíndrica, oblíqua e ortogonal. Processos usuais de perspectiva linear cônica. Sombras. Sombreados. Gráficos de Insolação. Cortes. Secções. Meias secções. Violações. Desenho preliminar e definitivo. Regras e convenções particulares de apresentação das principais técnicas. Detalhes. Gráficos. Croquis técnicos. Desenho de construção civil. Desenho de estruturas. Desenho topográfico. (UFPR, 1972a, s.p., negrito nosso).

As disciplinas do Departamento balizam a divisão em grupos de professores para a criação de comissões responsáveis por elaborarem um novo plano de ensino e os programas das disciplinas, que são eles: 1. Desenho Geométrico (Jayme M. Machado, Leonilda Auriquio e Augusto Conte); 2. Geometria Descritiva (José Cavallin, Jucundino Furtado e lldefonso C. Puppi); 3. Desenho Artístico (Roberto P. Alves e Orlando S. Pereira); 4. Desenho Técnico (Orlando S. Pereira e Lourenço Mourão); 5. Desenho de Observação e Croquis (Augusto Conte e Hayton Silva). Dos grupos formados, efetivam-se as alterações nas disciplinas de Desenho Geométrico I e II, no entanto não se aprova o programa de Desenho para Licenciatura em Ciências, com o intuito de que a comissão elabore um programa semelhante para Licenciatura em Ciências e Agronomia.

Mesmo que as demais disciplinas não tenham oficializado suas alterações, pelo exemplo dos Cursos de Licenciatura em Ciências e Agronomia podemos aferir sobre a funcionalidade do Departamento, em que a padronização de conteúdos disciplinares coloca em segundo plano as necessidades de cada graduação. A ideia de normatização dos conteúdos também é percebida pela condução das disciplinas de Nomografia ${ }^{21}$ e Desenho Geológico.

21 Plano de ensino de Nomografia: "Objeto e interesse da Nomografia. Notações. Escalas métricas e funcionais. Representação das equações a duas variáveis. Nomogramas cartesianos. Anamorfose. Nomogramas de 
Na primeira situação, o Departamento sugere a transferência da disciplina de Nomografia para o Departamento 04 do Instituto de Matemática; e, na segunda, o Departamento aconselha ao Curso de Geologia duas disciplinas já existentes (Desenho Técnico I e Geometria Descritiva I) e outra específica à área (UFPR, 1972d, s.p.).

Entendemos que a descrição dos planos de ensino aqui apresentados se justifica pelo valor histórico e documental dos dados, que, em síntese, pela retórica do corpo docente do Departamento e pelos conteúdos das ementas, apresenta uma divisão entre conteúdos do ciclo básico e profissionalizante - 0 desenho de construção civil, de estruturas e topográfico. Dentre as atividades dos professores, foram problematizados os dados disponíveis nas atas departamentais; no que diz respeito à trajetória profissional dos docentes, foi pontuada sua produção no âmbito das publicações disponíveis na própria Universidade - interligando ensino e pesquisa, atividades que competem ao docente do Ensino Superior nessa fase da instituição. Além da organização dos conteúdos e das disciplinas que o Departamento toma para si, consideramos que a permanência ou não de determinadas disciplinas irá moldar a carreira profissional dos professores de Desenho - conforme discussão no próximo tópico.

\section{Conjunto das disciplinas do Departamento: grupos e tipologias}

O concurso de professor assistente aberto pelo Instituto de Matemática da Universidade estava distribuído em cinco

escalas justapostas. Nomogramas de pontos alinhados. Representação das equações a três variáveis. Nomogramas cartesianos sem anamorfose. Nomogramas cartesianos com anamorfose. Nomogramas de retas convergentes. Nomogramas de pontos alinhados para equações a três variáveis. Classificação dos nomogramas. Construção dos nomogramas de terceira classe. Gênero zero e um. Construção dos nomogramas dos gêneros II e III. Representação das equações de quatro e mais variáveis, por alinhamentos múltiplos. [...]". (UFPR, 1972a, s.p.). 
grupos de no mínimo duas disciplinas, em que predominavam os conteúdos de Geometria Descritiva I, de acordo com a ata da reunião departamental de 24 de maio de 1972:

[...] opção I: a) Geometria Descritiva I, b) Geometria Descritiva II; opção II: a) Desenho Técnico I, b) Desenho Técnico II; opção III: a) Desenho Geométrico I, b) Desenho Geométrico II; Opção IV: Geometria Descritiva I, b) Desenho Artístico; opção V: a) Geometria Descritiva I, b) Desenho de Observação e Croquis. (UFPR, 1972g, s.p).

Em 14 de março de 1973, as disciplinas para o concurso foram reagrupadas, mantendo-se os conteúdos de Desenho Geométrico, Geometria Descritiva e Desenho Técnico e alterandose as demais:

Grupamento I - Desenho Geométrico I e Desenho Geométrico II; Grupamento II - Geometria Descritiva I, Geometria Descritiva II e Geometria Descritiva III; Grupamento III - Desenho Técnico I e Desenho Técnico II; Grupamento IV - Desenho Artístico I, Desenho Artístico II e Desenho de Observação e Croquis; Grupamento V Desenho Geométrico I e Nomografia. (UFPR, 1973c, s.p.).

No agrupamento IV, ficaram concentradas as disciplinas de Desenho Artístico I e Il e Desenho de Observação e Croquis, nas quais estavam incluídos os seguintes conteúdos:

Desenho de Observação e Croquis - Objetivos e aplicações do desenho nos cursos de Agronomia e Florestas. Materiais e técnicas especiais. Títulos e legendas. Letreiros ornamentais. Processos de reprodução e ampliação de desenhos. Processos e instrumentos adotados no desenho de vegetais, insetos e microorganismos e animais. Câmara clara, retro projetor e meios fotográficos. Aplicação das formas geométricas planas às formas naturais das folhas como estudo comparativo. Cópia por processos apropriados de assuntos da flora e fauna. Cortes de caules, raízes e frutas. Reprodução de 
lesões em geral. Diagrama de inflorescência. Tipos de enxertia. Tipos de antenas de insetos. Órgãos e aparelhos de insetos. Formas gerais de fungos. [...] Desenho Artístico I - Desenho de observação, com o emprego de várias técnicas e envolvendo o estudo das sombras própria e projetada, nos seguintes casos: claro-escuro no baixo relevo em gesso; modelo simples e sólidos geométricos; conjunto de modelos; sólidos geométricos regulares e irregulares; objetos de uso doméstico, isolados e em conjunto; objetos de uso comum, isolados e agrupados; conjunto de sólidos geométricos. Desenho Artístico II - Desenho de observação, com o emprego de várias técnicas e envolvendo o estudo das sombras, própria e projetada, nos seguintes casos: claro-escuro de ornatos em gesso ou não; o pé e a mão humanos em gesso; a cabeça e o busto em gesso; o corpo humano em gesso, no todo ou em parte; modelo vivo, envolvendo o busto, os pés e as mãos humanos; animais e aves. (UFPR, 1972a, s.p., negrito nosso).

Comparando-se a de março de 1973 com as duas propostas em janeiro e março de 1972, a tipologia das disciplinas por grupo apresenta uma divisão mais clara entre os grupos I, II e III, em relação aos grupos IV e V, tendo como base a versão de 1973. Os três primeiros com uma vertente mais técnica e os dois últimos com um direcionado ao desenho artístico e outro voltado à programação.

Pelo perfil das disciplinas e seu agrupamento para os concursos públicos, questionamos: qual vertente educacional corresponde ao Desenho ensinado pelo Departamento? Como operacionalizar a criação do Curso de Licenciatura em Desenho, retórica constante nas atas departamentais, diante da normatização dos conteúdos que prioriza as disciplinas de Desenho Geométrico, Geometria Descritiva e Desenho Técnico nessa fase embrionária do Departamento? $\mathrm{O}$ que configura $\mathrm{O}$ Departamento em sua fase embrionária?

Até então foram expostos assuntos elementares do Departamento. Em meados de 1973, tem-se o conjunto de disciplinas já estruturado com códigos e pré-requisitos, 
que permitem responder parte das indagações até aqui problematizadas. Constata-se que as disciplinas são ofertadas semestralmente e que atendem aos primeiros anos de formação dos alunos de graduação da Universidade, dentre as quais não têm pré-requisito as disciplinas: Desenho Geométrico I, Geometria Descritiva I, Desenho Artístico I e Nomografia. Pautando as disciplinas transcritas anteriormente com o conjunto do Quadro 1, vê-se que houve alteração de nomenclatura e de conteúdo. A disciplina de Desenho de Observação e Croquis passa a ser denominada de Desenho Técnico I - A, a qual atende ao curso de Agronomia e Florestal.

Quadro 1 - Disciplinas do Departamento 153 do Instituto de Matemática UFPR. Agosto, 1973.

\begin{tabular}{|l|l|c|c|c|c|c|}
\hline Código & Disciplinas & Semestre & Teóricas & Práticas & Créditos & Pré-requisito \\
\hline 153013 & Desenho Geométrico I & $1^{\circ}$ & 3 & - & 3 & - \\
\hline 153023 & Desenho Geométrico II & $2^{\circ}$ & 3 & - & 3 & 153013 \\
\hline 153034 & Geometria Descritiva I & $1^{\circ}$ & 3 & 2 & 4 & - \\
\hline 153044 & Geometria Descritiva II & $2^{\circ}$ & 3 & 2 & 4 & 153034 \\
\hline 153054 & Geometria Descritiva III & $3^{\circ}$ & 3 & 2 & 4 & 153044 \\
\hline 153063 & Desenho Artístico I* & $1^{\circ}$ & - & 6 & 3 & - \\
\hline 153073 & Desenho Artísitico II & $2^{\circ}$ & - & 6 & 3 & 153063 \\
\hline 153084 & Desenho Técnico I & $2^{\circ}$ & 2 & 4 & 4 & 153034 \\
\hline 153094 & Desenho Técnico II & $3^{\circ}$ & 2 & 4 & 4 & 153084 \\
\hline 153104 & Desenho Técnico I-A & $3^{\circ}$ & 2 & 4 & 4 & 153013 \\
\hline 153113 & Nomografia & $1^{\circ}$ & 3 & - & 3 & - \\
\hline
\end{tabular}

* Correquisito: Desenho Geométrico I.

Fonte: UFPR, 1973a, s. p.

A alteração do título da disciplina foi sugestão do professor Augusto Conte, conforme extrato da ata: 
[...] passando o 'Desenho de Observação e Croquis' a ter a denominação principal de 'Desenho Técnico I-A' código 153104, como 4 créditos e a seguinte ementa: 153104. DESENHO TÉCNICO I-A- DESENHO DE OBSERVAÇÃO E CROQUIS - Preliminaresletras, letreiros, títulos e legendas. Dupla projeção ortogonal e projeções cotadas. Elementos fundamentais-Rebatimento, processo de cópia. Reprodução de desenhos. Escalas. Cotagens. Esboços. Técnicas do desenho de vegetais, insetos e animais. Aplicação das formas geométricas planas às formas naturais das folhas. Cópia por processo apropriado de assunto da flora e fauna. Cortes de caules, raízes, folhas e frutos. Diagramas de inflorescência. Antenas de insetos e formas de insetos. Formas gerais de fungos. PRÉ-REQUISITO: DESENHO GEOMÉTRICO I. (UFPR, 1973a, s.p., negrito nosso).

Conte era membro da comissão responsável por elaborar o novo plano de ensino. Ao comparar-se com a primeira versão da disciplina, constata-se que foram acrescentados os conteúdos de dupla projeção ortogonal e projeções cotadas, elementos fundamentais do rebatimento, e excluídos os conteúdos de câmara clara, retroprojetor e meios fotográficos, aproximando a disciplina aos conteúdos trabalhados em Geometria Descritiva e Desenho Técnico. A alteração da nomenclatura, ${ }^{22}$ no transcorrer da história do Departamento, pode auxiliar na compreensão da trajetória de diferentes grupos sociais envolvidos com o ensino do Desenho, direcionado à formação de professores (Matemática e Desenho) e ao exercício profissional dos Cursos de Engenharia. Para Elias (2000), parte da pesquisa configuracional caracterizase por meio de uma análise processual dos fatos, os quais ocorrem

22 Hernández menciona que, para compreender as mudanças nas concepções e práticas da educação artística, deve-se recorrer à história do currículo. Ele considera que o "nome" que a disciplina foi tendo em cada contexto educacional sinaliza mudanças nas finalidades da educação em arte ou da educação no âmbito em geral, "assim, não se fala da mesma coisa quando são utilizadas denominações como desenho, expressão plástica, educação estética, educação visual e plástica”. (HERNÁNDEZ, 2000, p. 40). 
num tempo histórico e social determinado, categoria que será aprofundada a seguir.

\section{Ensino de Desenho no Setor de Ciências Exatas}

Este tópico abrange duas partes: a primeira mostra o período de transição dessa unidade administrativa, fase em que o antigo Departamento de Desenho e Geometria Descritiva passa a ser denominado de Departamento de Matemática Aplicada e Desenho; e a segunda simboliza o início da sua fase de consolidação, no qual passará a ser reconhecido como Departamento de Desenho ao romper seu vínculo com o Departamento de Matemática.

O Departamento 153 de Desenho e Geometria Descritiva foi absorvido pelo Departamento de Matemática Aplicada e Desenho. A nova denominação do Departamento coincide com o começo de suas atividades. ${ }^{23}$ Para pôr em funcionamento essa estrutura, foram nomeados pro tempore, como chefe e subchefe, os professores Orlando Silveira Pereira e Armando M. Teixeira de Freitas, respectivamente.

O professor Orlando esclarece que "o Departamento de Matemática Aplicada e Desenho ficou constituído pela soma do Departamento de Desenho e Geometria Descritiva e parte do Departamento de Computação e Estatística" (UFPR, 1973b, s.p.). Quanto às disciplinas, na ata da reunião departamental de 12 de dezembro de 1973, tem-se a nova conformação:

Desenho Geométrico I, Desenho Geométrico II, Geometria Descritiva I, Geometria Descritiva II, Geometria Descritiva III, Desenho Técnico I, Desenho Técnico I-A, Desenho Técnico II, Nomografia, Introdução à Computação Eletrônica, Processamento de Dados, Cálculo Numérico e Cálculo das Diferenças Finitas. (UFPR, 1973b, s.p.).

${ }^{23}$ Criado pelo Decreto n. 72717, de 29 de agosto de 1973. 
E, referente ao quadro docente, os professores são elencados de acordo com os seus planos de carreira, a saber:

TITULARES - José Cavallin, Jucundino da Silva Furtado, Orlando Silveira Pereira e Theodocio Jorge Atherino ${ }^{24}$ (Magnífico Reitor da UFPR); ADJUNTOS - Armando Muniz Teixeira de Freitas, Augusto Conte, Clion Dória, Eurico Dacheux de Macedo, Jayme Machado Cardoso, Jurandyr Pavão, Leonidas Aniceto de Souza e Lourenço da Silva Mourão; ASSISTENTES - Gilberto Azeredo Lopes, Jorge Bernard, Jose Ribeiro do Nascimento Junior, Leonilda Auriquio, Mila Aguilar e Roberto Portugal Alves; AUXILIARES DE ENSINO Afonso Celso C. Teixeira de Freitas ${ }^{25}$, Carlos Jorge Zimmermann ${ }^{26}$, Carlos Alberto Picanço de Carvalho ${ }^{27}$, Fernando Bley Vicente de Castro $^{28}$, Jurandyr Foltran, Ladislau Borges de Campos ${ }^{29}$, Manoel Jorge da Silva Junior, Olavo Del Claro Junior, Osni Stricker, Paulo Cesar Busnardo, Reynaldo Machado Bittencourt, Ronald Leal ${ }^{30}$,

24 Em 1965, apresentou sua tese para cátedra na Escola de Engenharia, referente à Matemática III - Cálculo numérico, intitulada: "Nomogramas de pontos alinhados: facilidade de sua construção e utilização". Entre outras publicações, citamos: "Matemática" (1970); "Introdução ao estudo da linguagem FORTRAN" (1972), em coautoria com Eurico Dacheux de Macedo e Akeo Tanabe; e "O fato e a fala" (1977).

Em 1986, defendeu sua dissertação: "Software empresarial qualidade ao longo do desenvolvimento", no Instituto Militar de Engenharia.

26 Em 1974, defende sua dissertação de mestrado intitulada "SIESTA - um sistema integrado estatístico conversacional", e, em 1984, publica o livro "Processamento interativo: a linguagem de programação APL".

27 Concluiu o mestrado em 1973, na Pontifícia Universidade Católica do Rio de Janeiro. A pesquisa tem como título "T-Automaton e particionamento de matrizes de transição". Finalizou o doutorado em 1979, na University of Waterloo, com a pesquisa "On program analysis with inequations and binary relation".

28 Em 1975, na Pontifícia Universidade Católica do Rio de Janeiro, finaliza a dissertação "Utilização de linguagem com manipulação de fórmulas para minimização de funções".

29 Publica os livros: "Álgebra matricial" (1983) e "Cálculo numérico" (1983).

30 Em 1974, defende o mestrado na Pontifícia Universidade Católica do Rio de 
Renato Emilio Coimbra e Robson Scardua; REGENTES - Elato Silva e Hayton Silva. (UFPR, 1973b, s.p., negrito nosso) ${ }^{31}$.

Nessa fase, o Departamento tem 34 professores, sendo que Theodocio Jorge Atherino e Eurico Dacheux de Macedo possuem cargos na Reitoria, Jayme Machado Cardoso e Carlos Alberto Picanço de Carvalho prestam serviços em outros departamentos. Essa configuração tem duração de seis meses, vigente de 12 de dezembro de 1973 até 15 de junho de 1974. A partir de então, o Departamento retoma seu molde inicial e recebe a denominação de Departamento de Desenho.

O Departamento continua com a mesma denominação até novembro de 2008, contudo o recorte aqui proposto aplica-se até 1977. Na conjuntura em questão, tanto as disciplinas, quanto os professores modificam sua conformação, o que permite aplicar o conceito de figuração de Norbert Elias, em que:

[...] uma Figuration é uma formação social, cujas dimensões podem ser muitas variáveis (os jogadores de um carteado, a sociedade de um café, uma classe escolar, uma aldeia, uma cidade, uma nação), em que os indivíduos estão ligados uns aos outros por um modo específico de dependências recíprocas e cuja reprodução supõe um equilíbrio móvel de tensões. (ELIAS, 2001, p. 13).

Para Elias, o objeto de estudo da sociologia tem como questão "saber de que modo e por que os indivíduos estão ligados entre si, constituindo assim, figurações dinâmicas específicas" (ELIAS,

Janeiro, com o tema "Um modelo probabilístico para avaliação e análise de desempenho de sistemas de programação".

31 Considerando os titulares, os adjuntos e os assistentes, de acordo com as unidades de origem, temos: 12 professores da Faculdade de Engenharia, 2 professores da Faculdade de Engenharia Química, 1 professor da Faculdade de Agronomia, 1 professor da Faculdade de Química e 2 professores da Faculdade de Filosofia. In: UNIVERSIDADE FEDERAL DO PARANÁ. Boletim Administrativo da Universidade Federal do Paraná, ano XVI, n. 194, jul. 1971, p. 5-6. 
2001, p. 13). Sua sociologia se opõe às categorias idealistas do indivíduo em si, o autor prefere pensar que a liberdade de cada indivíduo está sujeita a uma rede de dependências recíprocas, em que a ação de cada sujeito isolado depende de uma série de outras, que, por sua vez, modificam o jogo social. O conceito de figuração aparece em seu estudo sobre a sociedade de corte, no entendimento de que uma figuração não é fruto de um único indivíduo, mas se trata de como os indivíduos estão interligados e como sua situação social os une de modo particular (ELIAS, 2001).

Adotar a categoria figuração para o estudo do Departamento implica em que, nas análises das fontes, empreguemos o método configuracional. Esse método se opõe à pesquisa estatística, ou, muitas vezes, as análises quantitativas são a primeira etapa da análise sociológica que faz uso da pesquisa configuracional, no entendimento de que:

[...] a análise sociológica baseia-se no pressuposto de que todos os elementos de uma configuração, com suas respectivas propriedades, só são o que são em virtude da posição e função que têm nela. Assim, a análise ou separação dos elementos é meramente uma etapa temporária numa operação de pesquisa, que requer a complementação por outra, pela integração ou sinopse dos elementos, do mesmo modo que esta requer a suplementação pela primeira; aqui, o movimento dialético entre a análise e a síntese não tem começo, nem fim. (ELIAS, 2000, p. 58).

Neste estudo, o elo central da pesquisa configuracional parte da função social que cada docente toma para si no DDES, articulado em dois pontos: os conteúdos das disciplinas e sua permanência ou não como matriz do ensino de Desenho; o grupo de docentes que marca a fase embrionária dessa unidade administrativa, ponderando suas atividades no ensino da graduação e na pesquisa. ${ }^{32}$

32 Mapeou-se a produção acadêmica dos professores com base nas publicações disponíveis no Sistema de Biblioteca da UFPR (SiBi/UFPR), incluindo 
Considerando os cursos e os professores, entre 1975 e 1977 , o Departamento presta serviço às graduações de Matemática, Arquitetura e Urbanismo, Geologia, Licenciatura em Ciências, Desenho Industrial e Comunicação Visual; e às engenharias Civil, Química, Mecânica, Elétrica, Agronômica, Florestal e Cartográfica. De acordo com a escala de férias de 1976, o corpo docente do Departamento é constituído por 17 professores: Orlando S. Pereira, Jucundino da Silva Furtado, Augusto Conte, Clion Dória, Jurandyr Pavão, Lourenço da Silva Mourão, José R. do Nascimento Junior, Leonilda Auriquio, Gilberto Azeredo Lopes, Jorge Bernard, Mila Aguilar, Roberto Portugal Alves, Renato Emilio Coimbra, Hayton Silva, Antonio Mochon Costa, Joaquim Mancio da Silva, Milton de Macedo Cavalcanti. ${ }^{33}$ Ao comparar com a configuração anterior, sistematizada pela união dos departamentos no início de 1974, os professores Antonio Mochon Costa $^{34}$ e Milton de Macedo Cavalcanti iniciam suas atividades já nessa formatação.

Quanto às disciplinas, em 1975, há duas alterações em relação ao modelo aprovado anteriormente: primeiro, a mudança do nome da disciplina de Desenho de Observação e Croquis para Desenho Técnico III e a alteração do seu conteúdo; segundo, a adaptação das disciplinas de Desenho para Engenharia Civil, denominadas de Expressão Gráfica I (Geometria Descritiva) e Expressão Gráfica II (Desenho Técnico I e II).

mestrado, doutorado e livros.

33 Antonio M. Costa, Joaquim M. da Silva e Milton de M. Cavalcanti não constavam na relação de professores lotados no Departamento em abril de 1975; no entanto, ainda faziam parte do grupo os docentes José Cavallin e Jayme M. Cardoso. In: MINISTÉRIO DA EDUCAÇÃO E CULTURA/ UNIVERSIDADE FEDERAL DO PARANÁ. Fastos Universitários. v. 1, n. 5, maio 1975 , p. 424-425.

34 Em 1976, apresenta a dissertação de mestrado "Métodos para a solução do problema geodésico inverso mediante a representação esférica do elipsoide". De acordo com o Edital n. 01/77, o professor é aprovado no quadro permanente da UFPR na categoria Assistente. No mesmo edital, também foi aprovado o professor Roberto Alexandre Schelemm. In: MINISTÉRIO DA EDUCAÇÃO E CULTURA/UNIVERSIDADE FEDERAL DO PARANÁ. Fastos Universitários. v. 3, n. 7, jul. 1977, p. 3120. 
A mudança da disciplina de Desenho Técnico III justificase pela redução da carga horária semanal e pela falta de equipamento. O novo programa é apresentado por Augusto Conte, conforme extrato da ata da reunião departamental realizada em 21 de maio de 1976:

Explica o professor que o programa foi reduzido de uma carga horária de seis horas semanais para quatro horas semanais, e que permanecem no programa quatro pontos que exigem instrumental especial como fotografia, compasso de redução, câmara clara. Sem este aparelhamento é quase impossível dar aula, fazer representações no quadro negro não satisfaz. Sugere então a substituição destes quatro pontos por quatro outros de Desenho Técnico, existentes no programa anterior de seis horas. (UFPR, 1976a, s.p.).

A professora Mila Aguilar sugere que se mantenha o programa e que se explique que essa substituição de conteúdo é provisória, até que se adquiram os instrumentos necessários, conforme menção abaixo:

Dever-se-ia manter o programa original e colocar um adendo mencionando que os pontos: a) Processos e instrumentos adotados no desenho de vegetais e insetos, microorganismos e animais; b) Câmara-clara, retroprojetor e meios fotográficos; c) Reproduções de lesões em geral; d) Órgãos e aparelhos de insetos. Com exceção de meio fotográfico, seriam substituídos pelos seguintes: a) Dupla projeção ortogonal, representação dos elementos fundamentais; b) Escalas, cotagem e esboço. Generalidade; escala natural de redução e ampliação. Normas técnicas sobre cotas e linhas auxiliares de cotas. Esboço técnico e artístico; c) Noções sobre perspectiva cavaleira e isométrica, exercícios; d) Convenções topográficas. (UFPR, 1976a, s.p.).

O embate entre a posição dos professores é aprovado na reunião seguinte, em que o Departamento atende à sugestão de 
Augusto Conte. A legitimidade ou não do discurso proferido por cada professor remete-nos à colocação de Hernández, ao se fundamentar em Foucault para compreender como determinado modelo educacional se efetiva como padrão, na conexão entre formas de saber e estratégias de poder.

A legitimação se observa como expressão de um discurso por parte dos saberes reguladores da ação individual e social que age com a finalidade de representar e fixar a realidade mediante o desdobramento, de maneira visível e invisível, de elementos de controle da educação escolar, e, portanto, dos indivíduos. Para isso, os saberes organizados se constituem com a dupla função de excluir outros discursos (ao determinar o próprio) e fixar determinadas práticas sociais (legitimando-as com seu discurso). (HERNÁNDEZ, 2000, p. 63).

Percebe-se que tanto essa alteração, quanto a que foi realizada na disciplina de Desenho Técnico I-A sinalizam que - Departamento prioriza os conteúdos teóricos e técnicos da representação gráfica, condensados nas disciplinas de Desenho Geométrico, Geometria Descritiva e Desenho Técnico, consequentemente, os conteúdos do Desenho Artístico e as particularidades dos cursos são padronizados em função do perfil do Departamento. O posicionamento do Departamento de manter um "padrão" de disciplinas também se aplica à abertura de um conteúdo específico para o Curso de Geologia:

Outro assunto a seguir debatido foi a solicitação feita pela Coordenadoria do Curso de Geologia através do Of. n 132/76, indagando a possibilidade de o Departamento oferecer a disciplina de Desenho Geológico aos alunos do Curso de Geologia. Pergunta o Professor Presidente se cabe criar curso aqui ou não? O Setor de Ciências Exatas nada tem a ver com Desenho Geológico por outro lado Desenho Técnico III - para os cursos de Engenharia Agronômica e Florestal - já é uma exceção. (UFPR, 1976b, s.p.). 
Prosseguindo a análise em função da demanda do ano de 1977,35 as disciplinas ofertadas incluem: Desenho Geométrico I e II, Geometria Descritiva I e II, Nomografia, Desenho Técnico I, Desenho Técnico III, Expressão Gráfica I e II. Retomando Chervel, concluímos que esses três anos iniciais do DDES irão moldar a prática do professor de Desenho, já que, de acordo com o autor, as mudanças curriculares são processos lentos e se enraízam em função de um "modelo pedagógico" já aceito. O modelo aceito é o ensino de Desenho que atende aos cursos de Engenharia, cuja ênfase é o conteúdo básico de Desenho. A categoria figuração e o modelo configuracional de análise abrangem uma variedade de fontes e recursos metodológicos, aqui articulados em dois eixos: o ensino e a pesquisa. Concordando com Hernández, a presente pesquisa visa contribuir com as novas práticas de pesquisa histórica, ciente da função social e simbólica que o discurso científico assume diante da materialidade dos fatos - o que justifica a necessidade de materializar os conteúdos disciplinares que marcam o ensino de Desenho no Setor de Ciências Exatas em seus primeiros anos de gestão.

\section{Considerações finais}

Constatou-se que o DDES tinha seus professores originários do Instituto de Matemática, sendo a maioria dos docentes provenientes da unidade de Engenharia (SANTOS, 2012, p. 39-40). Também se percebe que a configuração proposta pelo "Departamento de Matemática Aplicada e de Desenho" teve uma duração temporária. $\mathrm{E}$, por fim, o DDES, que inicia sua trajetória institucional em 1974, atende três conteúdos: Desenho Geométrico, Geometria Descritiva e Desenho Técnico.

Dentre os interlocutores que participaram dessa etapa da

35 Nesse ano, de acordo com o Regimento do Setor de Exatas, aprovado na $22^{\mathrm{a}}$ reunião do Conselho Setorial, o Setor coordenava cinco departamentos, a saber: Matemática, Desenho, Informática, Química e Física. In: UNIVERSIDADE FEDERAL DO PARANÁ. Regimento do Setor de Ciências Exatas. p. 4. 
história do Departamento, destaca-se a atuação dos professores: Orlando Silveira Pereira, como chefe do Departamento; José Cavallin ${ }^{36}$, por representar a sustentação teórica dos conteúdos de Geometria Descritiva agregada aos livros produzidos nas décadas de 1950 e 1970; Augusto Conte, que tinha representatividade nas reuniões departamentais e conseguiu padronizar os conteúdos disciplinares; além dos docentes com cargos administrativos, os quais possuem volume de publicações, como Theodocio Jorge Atherino, Eurico Dacheux de Macedo e Idefonso Clemente Puppi.

Enfim, constatou-se que existe uma hierarquização de atividades entre os docentes e que a fase inicial do Departamento traz o peso da Reforma Universitária. Em decorrência da Reforma, tem-se uma retórica oficial que difere da ação habitual do professor. Isto é, oficialmente, a carreira do Magistério Superior não é mais regulamentada pelo regime de cátedra, no entanto ainda está internalizado pelo grupo o valor agregado ao tempo de serviço na instituição, indícios latentes: a) pela própria estruturação formal das atas que marcam a posição de cada professor pela classe; $b$ ) pela retórica constante entre os professores de que a existência do conteúdo de Desenho no vestibular melhoraria a qualidade dos alunos que ingressam no Ensino Superior; c) pelas lacunas referentes aos encargos didáticos dos professores.

Sobre as concepções educacionais e pedagógicas, tem-se o ensino de Desenho centrado numa vertente técnica direcionado aos cursos de Engenharia, porém, em paralelo, o Desenho tem um viés artístico. O Desenho como linguagem artística não é a opção escolhida pelo grupo, já que a preocupação inicial de se criar um Curso de Licenciatura em Desenho citada pelo corpo docente do Departamento de Desenho e Geometria Descritiva se efetiva pelo Departamento de Artes somente em 1983, ${ }^{37}$ com

36 Em 10 de março de 1976, a Universidade outorga o título de Professor Emérito, saudação feita por José Bittencourt de Paula. In: MINISTÉRIO DA EDUCAÇÃO E CULTURA/UNIVERSIDADE FEDERAL DO PARANÁ. Fastos Universitários. v. 2, mar. 1976, p. 426-429.

37 In: UNIVERSIDADE FEDERAL DO PARANÁ. Conselho de Ensino e Pesquisa. 
a criação do Curso de Educação Artística com as habilitações em Desenho e Artes Plásticas; pois, em 1975,38 é implantado primeiramente o Curso de Licenciatura em Educação Artística, de $1^{\circ}$ grau, transferindo a esse Departamento a formação do professor para o Ensino Básico.

\section{Referências}

BARBOSA, Ana Mae. Arte-educação no Brasil. São Paulo: Perspectiva, 2006.

BRASIL. Lei n. 4.024 de 20 de dezembro de 1961. Lei de Diretrizes e Bases da Educação Nacional. Disponível em: <http://presrepublica. jusbrasil.com.br/legislacao/108164/lei-de-diretrizes-e-base-de-1961lei-4024-61>. Acesso em: 15 jun. 2016.

BRASIL. Lei n. 5.540 de 28 de novembro de 1968. Disponível em: <http:// www2.camara.leg.br/legin/fed/lei/1960-1969/lei-5540-28-novembro1968-359201 publicacaooriginal-1-pl.html>. Acesso em: 15 jun. 2016.

BRASIL. Lei n ${ }^{\circ} 5692$ de 11 de agosto de 1971. Lei de Diretrizes e Bases para o ensino de $1^{\circ}$ e $2^{\circ}$ graus. Disponível em: <http://presrepublica. jusbrasil.com.br/legislacao/128525/lei-de-diretrizes-e-base-de-1971lei-5692-71>. Acesso em: 15 jun. 2016.

BRASIL. Ministério da Educação. Princípios norteadores das engenharias nos Institutos Federais. Brasília: MEC, 2009.

CHERVEL, André. História das disciplinas escolares: reflexões sobre um campo de pesquisa. Teoria \& Educação, Porto Alegre, n. 2, p. 77229, 1990.

Resolução n. 19/83 CEP. Fixa o currículo pleno do Curso de Educação artística.

38 In: UNIVERSIDADE FEDERAL DO PARANÁ. Conselho de Ensino e Pesquisa. Resolução n. 42/75 CEP. Fixa o currículo pleno do Curso de Educação artística. 
CUNHA, Luiz Antônio. Ensino superior e universidade no Brasil. In: LOPES, Eliane Marta Teixeira et. al. 500 anos de educação no Brasil. Belo Horizonte: Autêntica, 2015. p.151-204.

DEPARTAMENTO DE EXPRESSÃO GRÁFICA (DEGRAF) - UFPR. Ementas vigentes. Disponível em: <http://www.exatas.ufpr.br/portal/ degraf/ementas-vigentes/>. Acesso em: 10 nov. 2017.

ELIAS, Norbert. A sociedade de corte: investigação sobre a sociologia da realeza e da aristocracia de corte. Rio de Janeiro: Jorge Zahar, 2001.

ELIAS, Norbert. Os estabelecidos e os outsiders: sociologia das relações de poder a partir de uma pequena comunidade. Rio de Janeiro: Jorge Zahar, 2000.

GLASER, Niroá Zuleika Rotta Ribeiro. Educação na história da UFPR: apontamentos para uma minuta cronológica. Educar, Curitiba, v. 7, n. 1/2, p. 13-58, jan./dez. 1988.

HERNÀNDEZ, Fernando. Cultura visual, mudança educativa e projeto de trabalho. Porto Alegre: Artmed, 2000.

MACHADO, Rosilene Beatriz. Entre vida e morte: cenas de um ensino de desenho. 2012. 254 f. Dissertação (Mestrado em Educação Científica e Tecnológica) - Programa de Pós-Graduação em Educação Científica e Tecnológica, Universidade Federal de Santa Catarina, Santa Catarina, 2012.

MINISTÉRIO DA EDUCAÇÃO E CULTURA/UNIVERSIDADE FEDERAL DO PARANÁ. Fastos Universitários. v. 1, n. 5, maio 1975, p. 373-450.

MINISTÉRIO DA EDUCAÇÃO E CULTURA/UNIVERSIDADE FEDERAL DO PARANÁ. Fastos Universitários. v. 2, mar. 1976, p. 319-464.

MINISTÉRIO DA EDUCAÇÃO E CULTURA/UNIVERSIDADE FEDERAL DO PARANÁ. Fastos Universitários. v. 3, n. 7, jul. 1977, p. 3105-3234.

NASCIMENTO, Roberto Alcarria do. O ensino do desenho na educação brasileira. Apogeu e decadência de uma disciplina escolar. 1994. 120 f. Dissertação (Mestrado em Educação) - Programa de Pós-Graduação em Educação, Faculdade de Filosofia e Ciências, Universidade Estadual Paulista, São Paulo, 1994. 
OSINSKI, Dulce Regina Baggio. Arte, história e ensino: uma trajetória. 2. ed. São Paulo: Cortez, 2002.

PEREIRA, Orlando Silveira. Novo processo de perspectiva axonométrica. 1954. 52 f. Tese (Cátedra), Universidade Federal do Paraná, Curitiba, 1954.

SANTOS, Carlos Henrique dos et al. Sete décadas do Curso de Matemática da UFPR. Preprint, 2012.

UNIVERSIDADE FEDERAL DO PARANÁ. Atas das reuniões departamentais (DDES). 1971-1977:

. Ata da reunião departamental. 15 de setembro de 1971a.

. Ata da reunião departamental. 06 de janeiro de 1972a.

. Ata da reunião departamental. 22 de fevereiro de 1972b.

. Ata da reunião departamental.10 de março de 1972c.

.. Ata da reunião departamental. 17 de maio de 1972d.

. Ata da reunião departamental. 10 de janeiro de $1972 \mathrm{f}$.

. Ata da reunião departamental. 24 de maio de 1972g.

. Ata da reunião departamental. 30 de agosto de 1973a.

. Ata da reunião departamental. 12 de dezembro de 1973b.

. Ata da reunião departamental. 14 de março de 1973c.

. Ata da reunião departamental. 21 de maio de 1976a.

. Ata da reunião departamental. 30 de setembro de 1976b.

. Ata da reunião departamental. 06 de agosto de 1976c.

UNIVERSIDADE FEDERAL DO PARANÁ. Boletim Administrativo da Universidade Federal do Paraná, ano XV, n. 186, nov. 1970.

UNIVERSIDADE FEDERAL DO PARANÁ. Boletim Administrativo da Universidade Federal do Paraná, ano XVI, n. 193, jun. 1971.

UNIVERSIDADE FEDERAL DO PARANÁ. Boletim Administrativo da Universidade Federal do Paraná, ano XVI, n. 194, jul. 1971. 
UNIVERSIDADE FEDERAL DO PARANÁ. Boletim Administrativo da Universidade Federal do Paraná, ano XVIII, n. 220, set. 1973.

UNIVERSIDADE FEDERAL DO PARANÁ. Conselho de Ensino e Pesquisa. Resolução n. 42/75CEP. Fixa o currículo pleno do Curso de Educação artística.

UNIVERSIDADE FEDERAL DO PARANÁ. Conselho de Ensino e Pesquisa. Resolução n. 19/83 CEP. Fixa o currículo pleno do Curso de Educação artística.

UNIVERSIDADE FEDERAL DO PARANÁ. Projeto Político Pedagógico do Curso de Artes Visuais. Curitiba, 2007, s.p. Disponível em: <http:// www.sacod.ufpr.br/portal/artes/wpcontent/uploads/sites/8/2011/05/ ppp_introducao.pdf>. Acesso em: 4 abr. 2016.

UNIVERSIDADE FEDERAL DO PARANÁ. Regimento do Setor de Ciências Exatas. p.1-55. In: MINISTÉRIO DA EDUCAÇÃO E CULTURA/ UNIVERSIDADE FEDERAL DO PARANÁ. Fastos Universitários. v. 3, n. 10 , out. 1977. p. $3525-3638$.

Recebido em setembro de 2016. Aprovado em dezembro de 2017. 